\title{
A Closer Look at Vocational Rehabilitation College Training Services at the Virginia Department for the Blind and Vision Impaired
}

\author{
Deborah Collard ${ }^{1}$ \\ 1 Virginia Department for the Blind and Vision Impaired \\ Keywords: college training, visual impairment, vocational rehabilitation \\ https://doi.org/10.52017/001c.28182
}

\section{Rehabilitation Counselors and Educators Journal}

Vol. 10, Issue 2, 2021

\begin{abstract}
Working-age adults with visual impairments have an employment rate of $43.5 \%$, which was substantially lower than the employment rate (76.5\%) of those without disabilities (Krause et al., 2018). However, research involving both youth and adults with visual impairments has identified positive associations between educational attainment level, specifically post-secondary education and training, and employment (Cmar et al., 2018; Lund \& Cmar, 2019; Lund \& Cmar, 2020). The Virginia Department for the Blind and Visually Impaired (DBVI) sought to better understand the consumer demographics and employment outcomes of individuals receiving post-secondary education as part of the vocational rehabilitation (VR) program. This study found that younger individuals who received college training services were more likely to achieve higher earnings. Policies on college training services for individuals with blindness and visual impairments are discussed.
\end{abstract}

\section{Background and Purpose}

Individuals with disabilities consistently experience employment rates lower than peers without disabilities. In 2016, working-age adults with visual impairments had an employment rate of $43.5 \%$, which was substantially lower than the employment rate $(76.5 \%)$ of those without disabilities (Krause et al., 2018). The state-federal vocational rehabilitation (VR) program is designed to assist individuals with disabilities, including those with blindness and low vision, meet their employment goals. Financially supporting post-secondary education aligned with career goals is an allowable VR expense when integrated into a consumer's Individualized Plan for Employment (IPE). Research involving both youth and adults with visual impairments has identified positive associations between educational attainment level, specifically post-secondary education and training, and employment (Cmar et al., 2018; Lund \& Cmar, 2019, 2020).

During Federal Fiscal Year (FFY) 2017, the Virginia Department for the Blind and Vision Impaired (DBVI) experienced a substantial increase in the number of individuals served by the VR program. Historically, DBVI has expended a significant amount of VR funding on college training services for individuals participating in the VR program, with the total amount increasing substantially over the past ten years. To ensure an informed and equitable use of VR funds, DBVI was interested in taking a more focused look at col- lege training services, existing college training policy, and employment outcomes of individuals who received college training services as part of their VR program.

The purpose of the study was twofold. The first aim was to examine the population of individuals who received college training services and determine whether there was an effect of college training services on employment outcomes individuals obtained, as compared with individuals who did not receive college training services. The evaluation questions were:

1. What are the consumer demographics of those participating in post-secondary training?

2. Are there differences in the demographics between those who participate in post-secondary training and those who do not?

3. Do relationships exist between receipt of college services and VR employment outcomes?

4. Do relationships exist between receipt of college services and quality of employment (i.e., wage, occupation, hours worked)?

The second aim was to review other state VR agency college training policies to inform DBVI leadership in consideration for potential policy revisions.

\section{Methods}

The DBVI case management system (AWARE) and 
Table 1. Participant Demographics

\begin{tabular}{lcc}
\hline \multicolumn{1}{c}{ Demographic category } & With college training services $(\mathbf{n}=\mathbf{2 1 5})$ & Without college training services $(\mathbf{n}=\mathbf{1 , 5 8 4})$ \\
\hline Mean age & $35.4(\mathrm{SD}=12.1)$ & $45.2(\mathrm{SD}=14.4)$ \\
\% Female & 55 & 51 \\
\% Male & 45 & 49 \\
\% Asian & 1.4 & 3.1 \\
\% Black & 37.7 & 40.1 \\
\% Hispanic & 4.7 & 3.3 \\
\% White & 62.7 & 57.5 \\
\% Supported employment & 0.5 & 4.6 \\
\% SSI benefits & 25.1 & 17.4 \\
\% SSDI benefits & 44.7 & 46.3 \\
\% Significantly disabled (SD) & 80.0 & 76.2 \\
\hline
\end{tabular}

Table 2. Average Employment Outcomes for Those with and Without College Training Services

\begin{tabular}{lcc}
\hline & With college training services $(\mathbf{n}=138)$ & Without college training services $(\mathbf{n}=937)$ \\
\hline \% Rehabilitated & 64.2 & 59.2 \\
Hourly wage - mean & $\$ 16.15(\mathrm{SD}=\$ 10.66)$ & $\$ 16.19(\mathrm{SD}=\$ 13.61)$ \\
Weekly hours worked & 30.12 & 30.38 \\
\hline
\end{tabular}

RSA-911 data were used to examine the population of individuals who received college training services. The target population of the study was individuals who exited the VR program during FFY 2011 -2016 after IPE development. The following variables were pulled from the existing data: (a) individual characteristics (e.g., gender, age), (b) type of case closure, (c) occupations at closure, and (d) quality of employment as measured by hourly wage and hours worked. The data were examined using descriptive statistics tools in Microsoft Excel.

Additionally, policy manuals and documents from 16 state VR agencies were qualitatively reviewed to inform DBVI leadership regarding potential policy updates. The states selected were in close geographic proximity to Virginia, and states with similar population estimates. Four agencies specifically served individuals with blindness and visual impairments, and the number of customers was comparable to DBVI.

\section{Results}

\section{DBVI Consumer Data}

A total of 1,799 case records were reviewed for the study, including 215 (12.0\%) participants who received college training services as part of their VR program and 1,584 who did not. Both groups were similar in terms of gender, race, disability benefits status (i.e., SSI, SSDI), and disability priority status. However, individuals who were White, received Supplemental Security Income (SSI), and were determined significantly disabled represented a slightly higher proportion of individuals in both groups. In terms of age at ap- plication, the college training service group $($ mean $=35.4$; $\mathrm{SD}=12.1$ ) was significantly younger than their counterparts $($ mean $=45.2 ; \mathrm{SD}=14.4)$ as presented in Table 1 .

Overall, $64.2 \%$ of participants with college training services, compared with $59.2 \%$ without college training services, achieved an employment outcome. Regarding the relationship between individual characteristics and VR outcomes, age was identified as an important factor. Individuals aged 24 and younger with college training services were twice as likely to be employed when their VR case was closed (60\%) than those without (30\%). The gap was smaller for individuals aged 25 to 40 , which was $63 \%$ and 58\%, respectively.

Regarding the quality of employment of those who exited DBVI with a successful employment outcome, no notable differences were found between two groups. The average wages for those with and without college training services were $\$ 16.15$ (SD = \$10.66) and \$16.19 (SD = \$13.61), respectively. As such, no significant differences were found in the number of hours worked per week between two groups (see Table 2).

However, participant age was associated with the quality of employment; individuals aged 24 and younger with college training services earned higher hourly wages (mean = \$13.75) than those without (mean $=\$ 9.49)$, which indicates younger consumers might benefit more from college training services. The wage gap was smaller among those aged 25 to 40 : $\$ 15.66$ versus $\$ 14.63$. See Table 3 .

\section{Review of State VR Policy}

As a result of review of 16 other state VR agency policies 
Table 3. Employment Outcomes by Age for Those with and Without College Training Services

\begin{tabular}{ccccccc}
\hline & \multicolumn{3}{c}{ With college services } & \multicolumn{2}{c}{ Without college services } \\
\hline Age & Number & \% Rehab & Hourly wage - mean & Number & \% Rehab & Hourly wage - mean \\
\hline$<=24$ & 28 & 59.6 & $\$ 13.75$ & 110 & 30.4 & $\$ 9.49$ \\
$25-40$ & 64 & 63.4 & $\$ 15.66$ & 183 & 57.5 & $\$ 14.63$ \\
$41-64$ & 44 & 68.8 & $\$ 15.11$ & 323 & 63.3 & $\$ 15.26$ \\
$>=65$ & 2 & 66.7 & $\$ 12.54$ & 31 & 73.0 & $\$ 17.79$ \\
\hline
\end{tabular}

regarding sponsorship of college training services, six (38\%) require initial college training to occur at the community college level; eleven (69\%) have sponsorship limits, in-state requirements, or other state incentives specific for college training sponsorship; and five (31\%) have in-state requirements or other college sponsorship guidelines. Overall, the review demonstrated each state is using a variety of policies and incentives to address the potential cost of college training services. DBVI had similar policies in place and, as a step in considering potential policy changes, would need to revisit existing policy regarding sponsorship of college training services with VR staff to ensure policies were understood and implemented as written.

\section{Recommendations and Implications for Practice}

This study aimed to evaluate the effectiveness of college training services in relation to employment outcomes. While the results offer mixed support, some unexpected, yet interesting results emerged that can inform future efforts. This study found that younger individuals with college training services were more likely to achieve higher earnings and employment outcomes. College training is a high-cost service, so it is necessary to continue to monitor the current findings and include additional variables, such as level of education at the start of the VR program, the length of time an individual receives VR services, other types of VR services received, and previous employment experience. The qualitative and quantitative results of the study will be used as a resource to inform DBVI leadership regarding decisions on how to best utilize and direct agency resources to deliver college training services as part of the VR program. Based on this study, the following recommendations are offered:

- When designing a study that will be used to inform agency decision making, it is critical to understand the questions that decision makers are, or should be asking, including what information is most relevant. Specifically, consider if the purpose of the research is to guide budget development or funding requests, to ensure compliance with federal or state regulations, to strengthen policy guidance, or to assist with training for VR counselors and administrators.

- When working with a diverse data set or several data sets, spend time in the beginning of the project to organize and understand the information. Consider combining the information from different data sets in the most appropriate way to optimize the analysis.

- Over the last ten years, agencies have increasingly been considering the return-on-investment model for the provision of VR services, including college training services. Ultimately, post-secondary education and training should lead to employment outcomes with higher wages. This study helped identify where to focus college training service resources with individuals who are blind, and vision impaired within VR agencies.

\section{Author Note}

The contents of this paper were developed under a cooperative agreement with the U.S. Department of Education, Technical Assistance Center for Vocational Rehabilitation Agency Program Evaluation and Quality Assurance (PEQA-TAC) (Grant Award Number: H263B150004). However, the contents and views expressed in this publication do not necessarily represent the positions or policies of the U.S. Department of Education, and you should not assume endorsement by the Federal government. 


\section{References}

Cmar, J. L., McDonnall, M. C., \& Crudden, A. (2018). Transportation self-efficacy and employment among individuals with visual impairments. Journal of Vocational Rehabilitation, 48(2), 257-268. https://do i.org/10.3233/JVR-180925

Lund, E. M., \& Cmar, J. L. (2019). A systematic review of factors related to employment outcomes for adults with visual impairments. Journal of Visual Impairment \& Blindness, 113(6), 493-517. https://doi.org/10.1177/ $\underline{0145482 \times 19885211}$
Lund, E. M., \& Cmar, J. L. (2020). A systematic review of factors related to employment in transition-age youth with visual impairments. Rehabilitation Psychology, 65(2), 122-136. https://doi.org/10.1037/rep0000303 